\title{
Cuerpos extraños abdominales por maniobras abortivas
}

\author{
Por RAMON FRANCISCO SANCHEZ \\ Jefo de Clínica Obstétrica de la Universidad Nacional.
}

En una monogratia escrita hace ya algunos años, por las calendas en que jubilosamente ansiaba recibir el título de médico cirujano, comentaba los desastres biolóaicos y morales consecutivos al aboito criminal, y de paso me refería a los procedimientos absurdos a que apelan las famosas comadronas que en sus tugurios infernales satisfacen el grito egoísta de las marcadas con el látigo de fuego de la oratoria empenachada y arro. gante de un vigoroso panfletista $\mathrm{CO}$ lombiano.

Posteriormente Hernando Caicedo y Santiago Lleras publicaron en Heraldo Médico, juiciosas observaciones sobre el mismo tema. Hoy quiero dar a conocer dos historias clínicas interesantes por el hallazgo quirúrgico Y por la evolución, distinta afortunadamente a la mayoría de las de ese ayer, cuando aún no 80 conocíar los antibióticos y las mujeres rendian $c 0$. pioso tributo a la muerte.

Mondor, en su elásica monografía sobre los abortos mortales, trae toda una gama de procedimientos, ingenuos algunos y tremendamente malig. nos otros, como si el afín de interrum. pir un embarazo lluminara el camino de los sistemas hasta caer en el dominio de las extravagancias incuditas.

Pero mejor que cualquier comentario es el relato escueto de las historias siguientes, ambas del servicio del Profesor Acosta, en el Instituto de Protección Materna-Infantil de Bogotá.

\section{Observación número 1}

M. G. F., de 22 años, que ingresci el 14 de mayo de 1952. con amenorea desde el 29 de febrero, y que dice que el 12 de abril una "señora", le aplicó una sonda de grán calibre. la cual permaneció durante tres días en la vagina; como la mantobra no diese el resultado apotecido (el aborto), el 29 del mismo mes un "doctor" le pasó otra sonda y al día siguien. to le hizo un raspado y le formuló po.

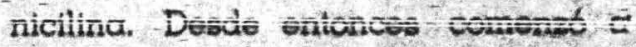
sentir dolor en el hipogastrio $y$ on las fosas llíacas y en el recto, fenómenos que, con el alza térmica, la obliga. ron a buscar refugio en el Hospital.

Al examen se ve una enferma en flaquecida, palida, febricitante; of hi. pogastrio es doloroso: hay defensa ab. 


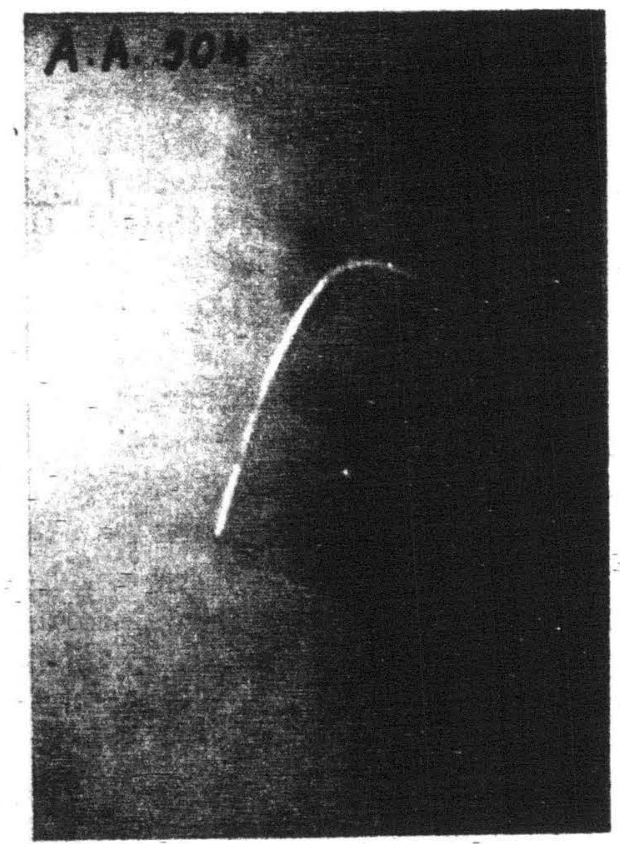

dominal y el cuello uterino es çorto. duro, cerrado; los fondos de saco están ocupados e impiden precisar - el contorno de la matriz.

Se la mantiene en observación, siguiendo un-tratamiento con penicilina, estreptomicina', dextrosa y duchas vaginales, mientras llegan los -siguien. tes resultados:

\section{Anćlisis de sangre:}

Hematies, 3.700.000.

Leusoctos, 16.000 .

Hemoglobina, $65 \%$.

Polinucleares neutrófilos, $82 \%$. Linfocitos pequetios, $12 \%$.

Formas de paso, 6\%.

Sedimentación a la $1 / 2$ hora, $60 \mathrm{~mm}$.

$y$ a la hora, $100 \mathrm{~mm}$.

Glucemia, 125 ma. \%.

N. P. N, $35 \mathrm{mg}, \%$.

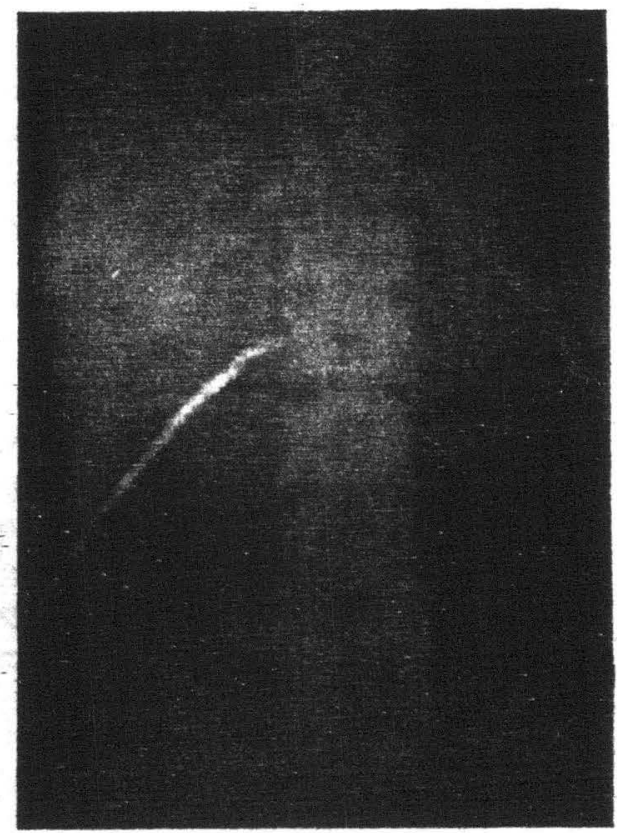

\section{Inćlisis de orina:}

Huellas de albúmina.

Piocitos $t+t$.

Hematios $t$ ?

Bacterias ++ .

Células $t+$.

Cilindros granulosos ++ .

\section{Examen radiográfico:}

Existe una sonda de Nelaton enrollada y al parecer dentro de la gran covidad pertioneal.

Con estos exćmenes, se intervie. ne, el 16 , bajo anestepia con ciclopro pano-éter-oxígeno. Se hace una lapa. rotomía media infraumbilical; el ac. ceso a la pelvis es difícll por gron cantidad de adherencias epiplóicas $\theta$ in. testinales a la pared y órganos intrapelvianos y por haber múltiples abs. 
cesos: pero cuidadosamente se logra hallar un extremo de la sonda, que se extrae después de romper un absceso y de salir gran cantidad de pus cremoso y bien ligado. Se deja sulfa. tiazol en la cavidad y se cierra.

A la semana siguiente, la enferma se encuentra en buenas condiciones y sale el 24 de mayo. Post-operatorio apenas subfebrit.

\section{Observación número 2}

A. A. de 27 crños, ingresa el 13 de febrero. Es una multigestante, en amenorrea desde el 5 de noviembre, y que llega al servicio con ligera hemorragia genital y -relatando una historia de una caída a consecuencia de la cual principió a sangrar. Se le hace un tacto y él nos demuestra un cue-

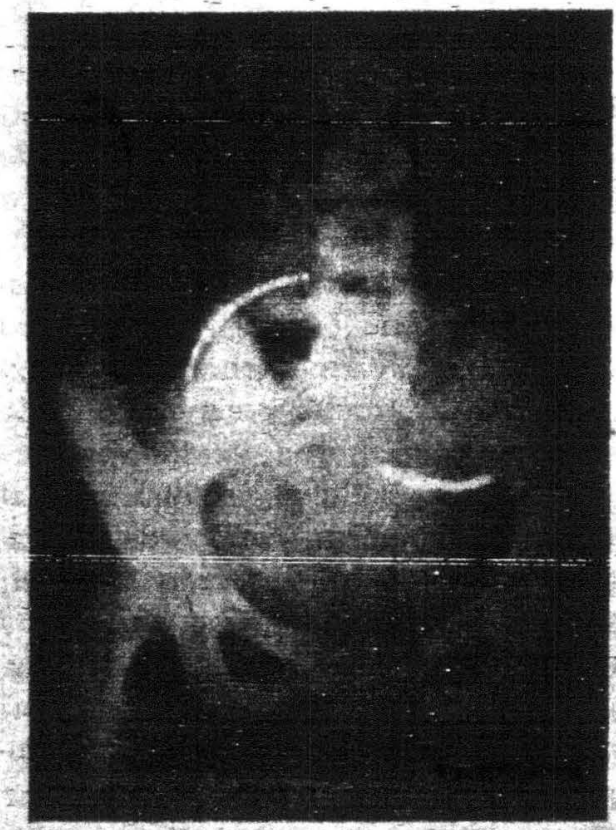

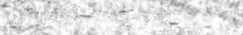

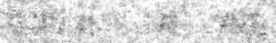

llo duro, entreableito, tondos do saco libres y matriz grande, como con embarazo de dos meses. Se plensa en una amenaza de aborto o en aborto incompleto y se la pone en observación. A los cinco días, el cuadro se ha modificado: hãy vómito, fiebre, dolor epigástrico y defensa abdominal alta. Esto sugiere unci afección gás irlca o duodenal y de ahi que se le formule ludozán, dieta y alcalinos y se le ordene un examen radiográfico. El radiólogo dice que "se encuentra un cuerpo extraño (sonda), alojado en el flanco derecho del abdomen y al parecer dentró de la cran cavidad peritoneal". No obstante la evidencia radiológica, la paciente continúa mintiendo, pero al fin se convence de la inutilidad de su relato ficticio y confiesa con lujo de detalles las maniobras a que la sometió una comadrona.

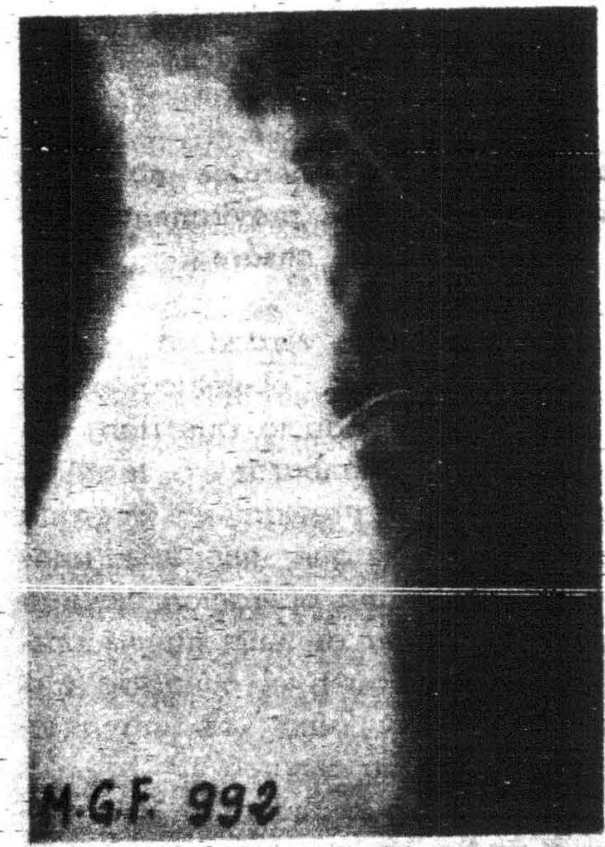


t! b de marzo, se mervient hachen

do una laparotomía mediana supraumbilical. Los tejidos están acartonados, duros e-invadidos por colecciones purulentas múltiples hasta el tejido celular subcutáneo. Se aspira esta supuración y por un ojal se extrae la sonda. Como es imposible reconstruir planos, se sutura en uno solo peritoneo y aponeurosis, previa colo cación de sulfa local. En el post-ope ratorio se dan antibióticos. La tempe. ratura oscila entre 39 y 37 grados y el 19 sale por completa curación.
Hematíes, 4.670.000.

Leucocitos, 12.400 .

Hemoglobina, $80 \%$.

Valor globular, 0,8 .

Neutrófilos, 76.

Eosinófilos, 3.

Linfocitos, 19.

Formas de paso, 2.

Sedimentación:

A la $1 / 2$ hora, $56 \mathrm{~mm}$.

A la hora, $110 \mathrm{~mm}$.

Glucemia, $0,89 \%$, y

N. P. N., 27 mg. $\%$.

\section{Conducta obstétrica en las mujeres previamente operadas de cesárea}

\section{Por el doctor MARIO SANZ ARAOS}

\section{CAPITULO 1}

\section{Conildercueiones generales sobre el parto, en pacientes previamente ope- radas de cesćrea.}

Existe aún una verdadera contro versia en el campo obstétrico en ro lación con la conducta que debe se guirse ante un embarazo a término. en una paciente previamente operada de cesárea, ya que mientras unos sostienen que una operación cesárea no es indicación de una nueva ope ración, otros siguen el conocido atorismo que dice: "una vez una cesárea, siempre una cesárea".

En verdad, la realidad de este alo rismo, podía ser absolutamente cierta cuando se practicaba la cesárea cor- poral sistemáticamenie, sobre todo. teniendo en cuenta el dato que daba Holland, quien decía que el $20 \%$ de las rupturas uterinas eran debidas a - la cescárea corporal.

Pero la técnica moderna de la operación cesárea, es decir, la cesárea segmentaria transperitoneal, ha ablerto nuevos horizontes para el futuro de la mujer con cesárea previa.

El mismo Holland asegura que el $4 \%$ de las rupturas uterinas del emba. razo se deben a la cesárea comporai sin embargo, desde que se viene practicando la cesćrea segmentoria trans. peritoneal, no se ha presentado aun en nuestro medio, un solo caso comprobado de ruptura espontánea del útero, durante el embarazo. Es más, se puede asegurar, que las rupturas 